\title{
Smoking and spondyloarthritis: a bad connection
}

\author{
Daniel Wendling ${ }^{1,2} \cdot$ Clément Prati $^{1,3}$
}

Received: 28 August 2015 / Accepted: 18 September 2015 / Published online: 13 October 2015

(C) Springer-Verlag Berlin Heidelberg 2015

Spondyloarthritis is a chronic disease encompassing several phenotypic subsets, and potentially disabling with impaired functional capacities, with socioeconomic consequences as the disease affects mainly young adults. The pathophysiological mechanisms leading to the disease are partially unknown, but involve genetic and environmental factors such as gut microbiota [1], as well as some imbalance in immunological regulations, particularly the IL-23/ Th17 axis [2].

A body of evidence became available over the years for a deleterious influence of smoking upon spondyloarthritis (SpA) [3], and particularly ankylosing spondylitis (AS), a subset of axial spondyloarthritis with radiographic evidence. Smoking is associated with more active and severe diseases [3], even in early disease [4] with structural damage assessed by radiographic scoring [5]. In a populationbased study in Norway, incident AS was associated with current smoking [6]. Moreover, some studies argue for impairment of therapeutic response to TNF blockers in smokers with axial spondyloarthritis [7].

In this issue, Sakellariou et al. [8] confirm previous results with a cross-sectional study in another population with different genetic background. The authors found in a population of more than 100 anti-TNF-naive AS patients in multivariate analysis that current smoking was

Daniel Wendling

dwendling@chu-besancon.fr

1 Department of Rheumatology, University Teaching Hospital, CHRU de Besançon, Boulevard Fleming, 25030 Besançon, France

2 EA 4266, Université de Franche-Comté, Besançon, France

3 FDE EA4267, (FHU INCREASE) Univ. Bourgogne FrancheComté, 25000 Besançon, France independently associated with a higher BASDAI score (disease activity), and that increasing pack years were independently associated with higher mSASSS (radiographic spine damage), and a tendency with higher BASFI (function). These results are in accordance with the published data.

But beyond these findings, the emerging question is the precise mechanism explaining the link between smoking and inflammation, disease activity, and new bone formation related to the disease.

Several pathways may be followed and explored in this relationship.

As recalled in the above-mentioned paper, smoking has an inflammatory effect through increased production of pro-inflammatory cytokines such as TNF-alpha and IL-6. In axial SpA, this was suggested by the finding of a smoking dose-dependent rise of CRP levels [5].

Periodontitis may also play a role in the disease, as frequent association was noticed in several studies [9]. Smoking is associated with periodontitis and its severity in a dose-dependent manner and correlated with CRP elevation [10].

Smoking may also interfere with gut physiology. Gut involvement appears increasing in the pathophysiological determination of $\mathrm{SpA}$ [1], through different implications, and particularly gut dysbiosis. Smoking was demonstrated to alter intestinal microbiota as well in IBD as in healthy subjects [11].

IL-23/Th17 pathway has a major implication in spondyloarthritis [2]. In animal models, it was demonstrated that chronic cigarette smoke exposure resulted in increase in lung Th 17 cell prevalence, and Th17-related cytokines (IL17A, IL-6, IL-23) [12], suggesting the possibility of activation of the IL-23/Th17 pathway by smoking.

Another issue is the impact of smoking upon new bone formation in axial spondyloarthritis, as smoking is 
associated with radiographic progression in this disease, assessed by the mSASSS score, which quantifies predominantly ossification on the vertebral corner. The underlying new bone formation process at the entheses modulated by smoking remains to be demonstrated. New bone formation in ankylosing spondylitis is a complex process [13], involving several kinds of molecules, in particular bone morphogenetic proteins (BMP), and osteoblast signaling pathway markers (Wnt for example) and their inhibitors (DKK-1). Some data suggest an effect of smoking on mRNA expression of BMP in periosteum [14], and this may deserve further investigation.

Endothelial dysfunction is also associated with ankylosing spondylitis and may be one of the mechanisms leading to increased vascular and cardiovascular morbidity and mortality in this disease [15]. Some biologic markers of endothelium (vascular endothelial growth factor, VEGF) were evaluated in the serum of patients with AS, correlated with disease activity and predictive of radiographic progression [16]. Smoking impairs endothelial function; this has been demonstrated in healthy subjects [17], and this may contribute to increased activity and structural damage in SpA smokers.

Finally, smoking may influence epigenetic regulation processes. Many systems are involved in epigenetic control of inflammatory diseases. Sirtuin 1 (Sirt1) is a nuclear enzyme from the class III histone deacetylases (HDACs) modulating the expression of genes, including those regulating the IL-23/Th17 pathway, sclerostin/Wnt pathways, and autophagy, which have all been incriminated in spondyloarthritis (SpA). An exploratory study found that Sirt1 activity from PBMC was lower in SpA patients without NSAIDs compared to controls [18]. Sirt1 is also implicated in endothelial function reduction, and in vitro experiments suggest that cigarette smoke-mediated reduction of Sirt1 is associated with endothelial dysfunction [19].

Factors linked to smoking should also be investigated. The potential role of depression should be analyzed. Depression is associated with smoking, and with spondyloarthritis in some studies.

Obviously, there are several potential underlying factors (that may be additional) to link smoking and spondyloarthritis and disease activity. A better understanding of these mechanisms would give new insight into the knowledge of the disease. Many questions remain unanswered to date about this topic. Since cigarette smoking is a complex mixture of numerous agents, which compound(s) in cigarette smoke is responsible for these deleterious effects? The answer to this question would represent a major step forward.

The next step will be interventional studies, evaluating the impact of smoking cessation upon disease activity and long-term outcomes (radiographic damage). This will need large groups of patients and prolonged follow-up.

Paying attention on smoking in the management of patients with spondyloarthritis is worthwhile. Smoking appears as a prognostic factor of poor outcome, as well as a known risk factor for cardiovascular morbidity (already increased by the inflammatory disease itself). Smoking cessation is a primary care measure, part of some national recommendations for spondyloarthritis management [20], which should be applied to every patient presenting with the disease.

\section{Compliance with ethical standards}

Conflict of interest The authors declare no conflict of interest concerning this paper.

\section{References}

1. Wendling D, Vuitton L, Koch S, Prati C (2015) Spondyloarthritis and the gut: a new look. Joint Bone Spine 82:77-79

2. Wendling D, Guillot X, Prati C (2015) The IL-23/Th 17 pathway in spondyloarthritis: the royal road? Joint Bone Spine 82:1-4

3. Wendling D, Prati C (2013) Spondyloarthritis and smoking: towards a new insight into the disease. Expert Rev Clin Immunol 9:511-516

4. Chung HY, Machado P, van der Heijde D et al (2012) Smokers in early axial spondyloarthritis have earlier disease onset, more disease activity, inflammation and damage, and poorer function and health-related quality of life: results from the DESIR cohort. Ann Rheum Dis 71:809-816

5. Poddubnyy D, Haibel H, Listing J et al (2013) Cigarette smoking has a dose-dependent impact on progression of structural damage in the spine in patients with axial spondyloarthritis: results from the GErman SPondyloarthritis Inception Cohort (GESPIC). Ann Rheum Dis 72:1430-1432

6. Videm V, Cortes A, Thomas R, Brown MA (2014) Current smoking is associated with incident ankylosing spondylitis- the HUNT population-based Norwegian health study. J Rheumatol 41:2041-2048

7. Ciurea A, Scherer A, Weber U et al (2015) Impaired response to treatment with tumour necrosis factor $\alpha$ inhibitors in smokers with axial spondyloarthritis. Ann Rheum Dis. doi:10.1136/ annrheumdis-2013-205133

8. Sakellariou GT, Anastasilakis AD, Kenanidis E, Potoupnis M, Tsiridis E, Savvidis M, Kartalis N, Sayegh FE (2015) The effect of smoking on clinical and radiographic variables, and acute phase reactants in patients with ankylosing spondylitis. Rheumatol Int. doi:10.1007/s00296-015-3381-3

9. Ratz T, Dean LE, Atzeni F et al (2015) A possible link between ankylosing spondylitis and periodontitis: a systematic review and meta-analysis. Rheumatology (Oxford) 54:500-510

10. Azizi A, Sarlati F, Bidi M et al (2015) Effects of smoking severity and moderate and severe periodontitis on serum C-reactive protein levels: an age- and gender-matched retrospective cohort study. Biomarkers 31:1-7

11. Biedermann L, Brülisauer K, Zeitz J et al (2014) Smoking cessation alters intestinal microbiota: insights from quantitative investigations on human fecal samples using FISH. Inflamm Bowel Dis 20:1496-1501 
12. Wang H, Peng W, Weng Y (2012) Imbalance of Th17/Treg cells in mice with chronic cigarette smoke exposure. Int Immunopharmacol 14:504-512

13. Wendling D, Claudepierre $P$ (2013) New bone formation in axial spondyloarthritis. Joint Bone Spine 80:454-458

14. Chassanidis CG, Malizos KN, Varitimidis S et al (2012) Smoking affects mRNA expression of bone morphogenetic proteins in human periosteum. J Bone Joint Surg Br 94:1427-1432

15. Prati C, Demougeot C, Guillot X et al (2014) Endothelial dysfunction in joint disease. Joint Bone Spine 81:386-391

16. Poddubnyy D, Conrad K, Haibel H et al (2014) Elevated serum level of the vascular endothelial growth factor predicts radiographic spinal progression in patients with axial spondyloarthritis. Ann Rheum Dis 73:2137-2143
17. Miyata S, Noda A, Ito Y et al (2015) Smoking acutely impaired endothelial function in healthy college students. Acta Cardiol 70:282-285

18. Wendling D, Delattre E, Abbas W et al (2015) Sirt-1 activity in PBMC from patients with spondyloarthritis. Joint Bone Spine $82: 210-211$

19. Arunachalam G, Yao H, Sundar IK et al (2010) SIRT1 regulates oxidant- and cigarette smoke-induced eNOS acetylation in endothelial cells: role of resveratrol. Biochem Biophys Res Commun 393:66-72

20. Wendling D, Lukas C, Paccou J et al (2014) Recommendations of the French Society for Rheumatology (SFR) on the everyday management of patients with spondyloarthritis. Joint Bone Spine $81: 6-14$ 